\title{
Quantitative Investigations about the Surface Texture Characteristics of the Nickel-Carbon Composite Thin Films using Stereometric Analysis
}

\author{
Aleksandra ADAMIEC ${ }^{1}$, Sebastian STACH ${ }^{1}$ and Ştefan ŢĂLU ${ }^{2, *}$ \\ ${ }^{1}$ University of Silesia, Faculty of Computer Science and Materials Science, Institute of Informatics, Department of Biomedical \\ Computer Systems, Będzińska 39, 41-205 Sosnowiec, Poland \\ ${ }^{2}$ The Technical University of Cluj-Napoca, The Directorate of Research, Development and Innovation Management (DMCDI), 15 \\ Constantin Daicoviciu Street, Cluj-Napoca, 400020, Romania \\ ${ }^{*}$ Corresponding author
}

\begin{abstract}
The purpose of this study was to describe the 3-D nano-scaled surface texture of the Nickel-Carbon (Ni-C) nanocomposite thin films composed of $\mathrm{Ni}$ nanoparticles with different average sizes embedded in amorphous hydrogenated carbon using stereometric analysis. The 3-D nanoscaled surface texture was studied by atomic force microscopy (AFM) and stereometric analysis. In a wider context, we also discuss our findings with regard to manufacture of the Nickel-Carbon composite thin films with desired surface characteristics.
\end{abstract}

Keywords-atomic force microscopy; Nickel-Carbon composite thin films; stereometric analysis; surface micromorphology

\section{INTRODUCTION}

Nickel is conductor, hard and ferromagnetic at room temperature. Due to a layer of its oxide acting as a protection, it is corrosion-resistant, so its thin layers are used to cover other metals to prevent corrosion, which has many uses for the production of industrial tools [1-3].

Carbon nanocomposites containing metal nanoparticles in the carbon amorphous environment have attracted the attention of researchers owing to their interesting physical applications to investigate their application in various industrial and medical fields [4-6], and they can also be used as coating materials in electronics, spintronics, optics, biomedicine, and ferroelectric memories [7-9].

Thus, the researchers, with changes in the method and conditions for the construction of these thin layers or even small changes in the composite structure, create various physical properties in them. Therefore, control over the method, fabrication conditions, and impurities of metal-carbon thin film can lead to control over structural properties and, consequently, other physical properties [10-19].

A nickel-carbon thin film is considered and studied used as an optical coating, a catalyst, and a water splitting electrode [20, 21].

In this article, stereometric analyses have been carried out to investigate the 3-D surface texture of engineered composite surfaces of Nickel-Carbon, which have been imaged using AFM.

\section{MATERIALS AND METHODS}

\section{A. Materials}

$\mathrm{Ni}-\mathrm{C}$ composite thin films were prepared by the methodology described elsewhere [1]. Producing the nickel nanoparticles in carbon bed is performed using RF-PECVD in acetylene gas environment. In this system, the chamber is vacuumed using rotary and diffusion pumps up to $10^{-5} \mathrm{bar}$, and the chamber consists of two electrodes, one as the target electrode (nickel) and the other as a substrate. Next, the glass substrate with $1 \times 1$ dimensions is placed inside the chamber on the electrode attached to earth, and acetylene gas enters the compartment to adjust the functioning pressure. The RF power is then applied to create the plasma and begin sputtering. For all samples (target: Nickel) were used next sputtering parameters: basic pressure $10^{-5}$ [mbar]; work pressure 0.025 [mbar]; power $250[\mathrm{~W}]$. The deposition time was varied in different experiments for samples: A) 7 min; B) 10 min and C) $13 \mathrm{~min}$.

\section{B. Methods}

The parameters related to the surface texture of the films were investigated using atomic force microscopy (AFM) analysis. MountainsMap ${ }^{\circledR}$ Premium software was used in the analysis of surface topography [22]. The software makes use of advanced tools and is compatible with the AFM microscopy.

\section{RESUlTS}

The measurement data of the samples of three different deposition periods were entered into MountainsMap ${ }^{\circledR}$ Premium in order to analyze the samples (Figures: I, II and III).

First of all, the images were leveled by subtraction using the following method: the LS plane and shape deletion operation was employed. 


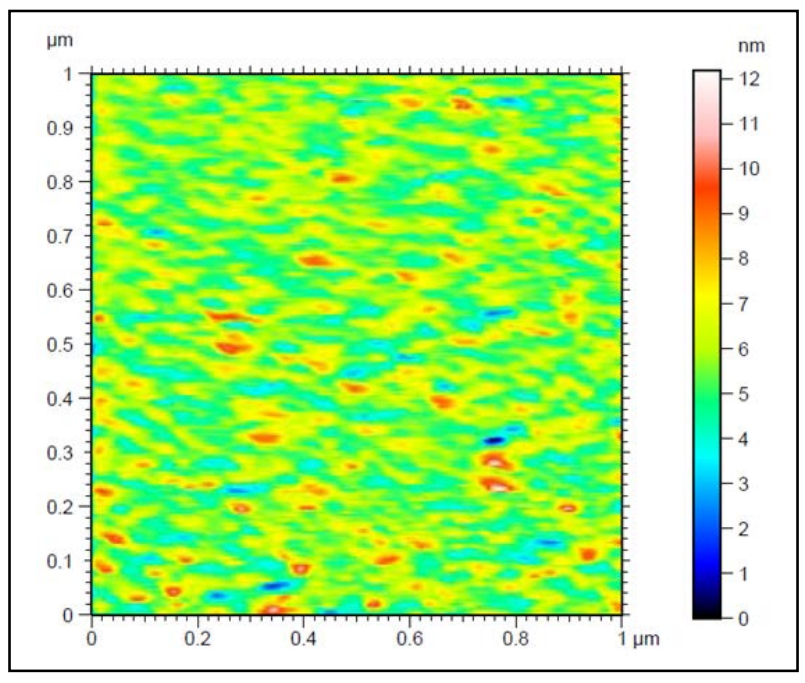

FIGURE I.

THE AFM IMAGE OF THE SAMPLE: A

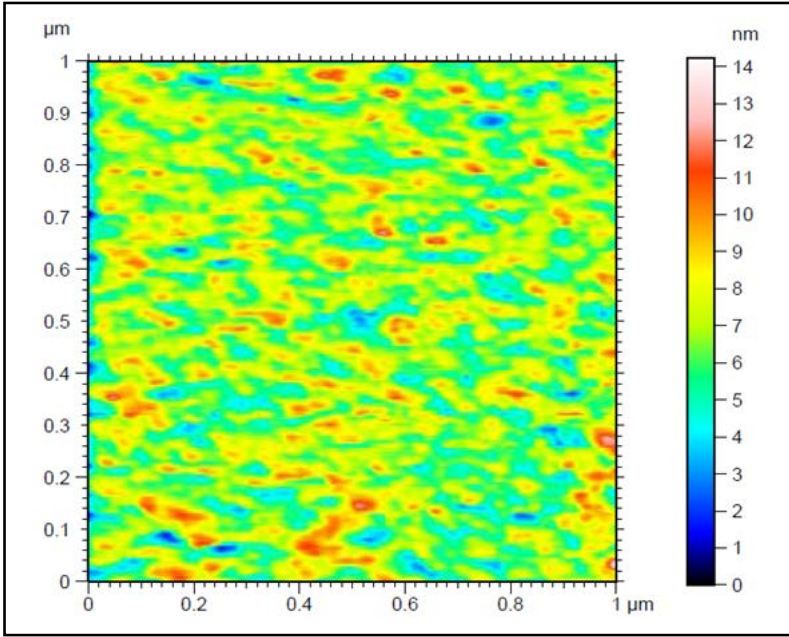

FIGURE II.

THE AFM IMAGE OF THE SAMPLE: B

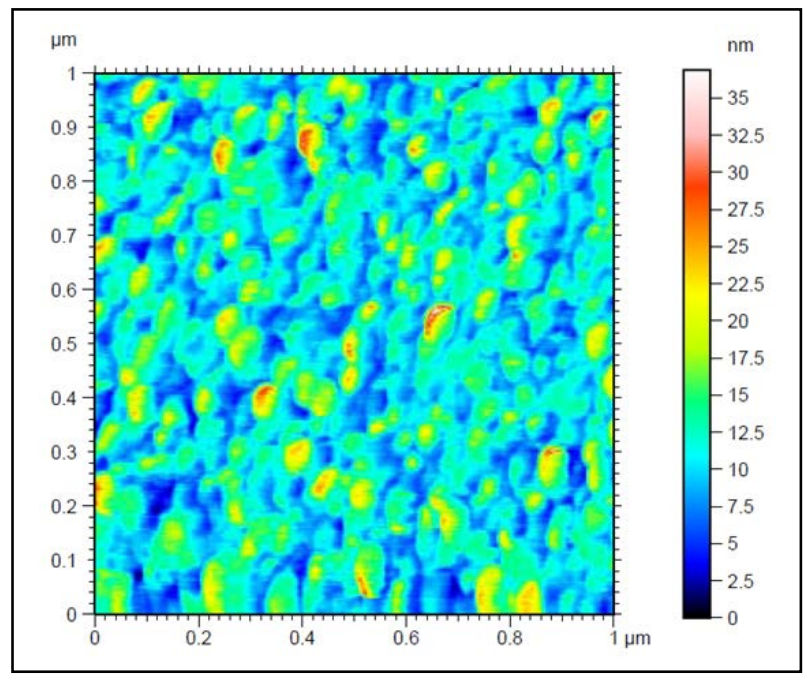

FIGURE III.
Secondly, identification cards including basic information about the samples (e.g. length, size, spacing, offset) were prepared. The data included in the cards were collected in Table I.

TABLE I. INFORMATION FROM THE IDENTIFICATION CARDS OF ALL THREE SAMPLES

\begin{tabular}{|c|c|c|c|}
\hline & Sample 1 & Sample 2 & Sample 3 \\
\hline \multicolumn{4}{|c|}{ AXIS: X } \\
\hline Length $[\mu \mathrm{m}]$ & 1,00 & 1,00 & 1,00 \\
\hline Size [points] & 256 & 256 & 256 \\
\hline Spacing [nm] & 3,92 & 3,92 & 3,92 \\
\hline Offset $[\mu \mathrm{m}]$ & 0,00 & 0,00 & 0,024 \\
\hline \multicolumn{4}{|c|}{ AXIS: Y } \\
\hline Length $[\mu \mathrm{m}]$ & 1,00 & 1,00 & 1,00 \\
\hline Size [lines] & 256 & 256 & 256 \\
\hline Spacing [nm] & 3,92 & 3,92 & 3,92 \\
\hline Offset $[\mu \mathrm{m}]$ & $-1,0$ & $-1,0$ & $-1,02$ \\
\hline \multicolumn{4}{|c|}{ AXIS: Z } \\
\hline Length [nm] & 12,2 & 14,2 & 0,00 \\
\hline $\mathrm{Z} \min [\mathrm{nm}]$ & $-5,71$ & $-6,8$ & 0,00 \\
\hline $\mathrm{Z} \max [\mathrm{nm}]$ & 6,48 & 7,44 & 0,00 \\
\hline $\begin{array}{l}\text { Size [decimal place } \\
\text { values] }\end{array}$ & 159160 & 905994 & 0 \\
\hline Spacing [pm] & 0,0766 & 0,0157 & 0,273 \\
\hline
\end{tabular}

Thirdly, the 3-D image for each sample was generated. The image has a scale, graduation and axis system (Figures IV-VI).

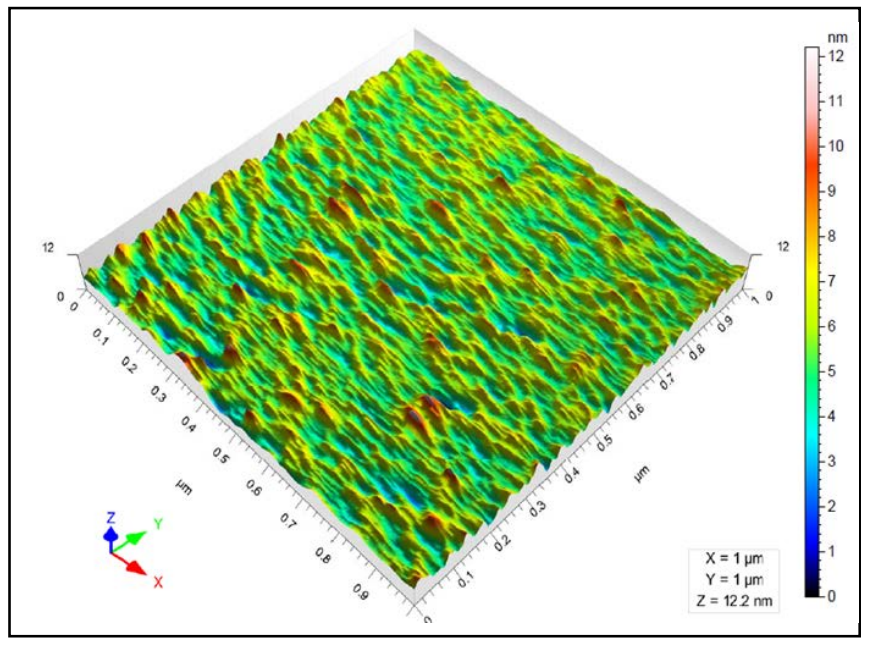

FIGURE IV.

THE AFM 3D IMAGE OF SAMPLE A 


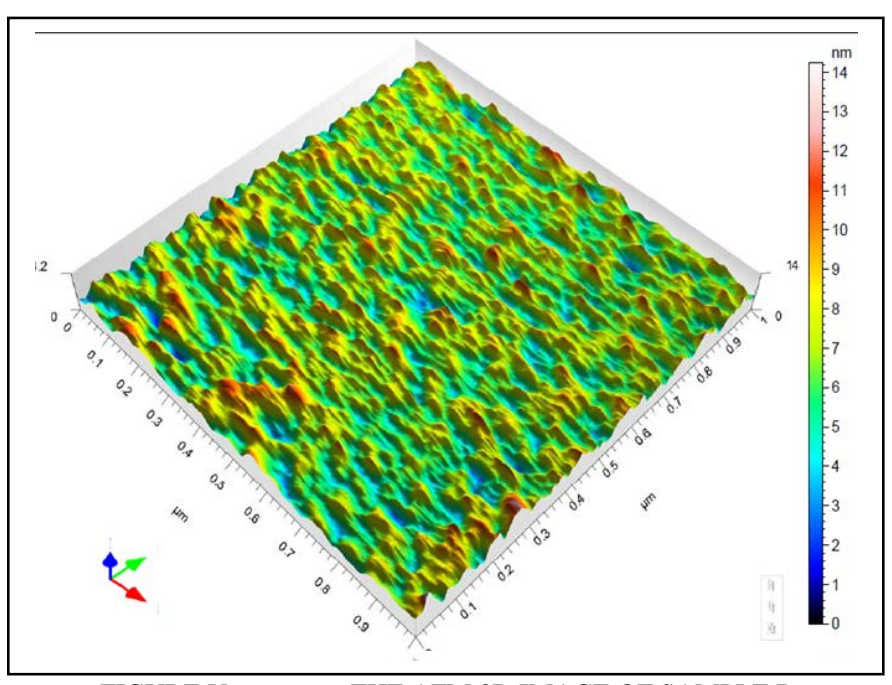

FIGURE V.

THE AFM 3D IMAGE OF SAMPLE B

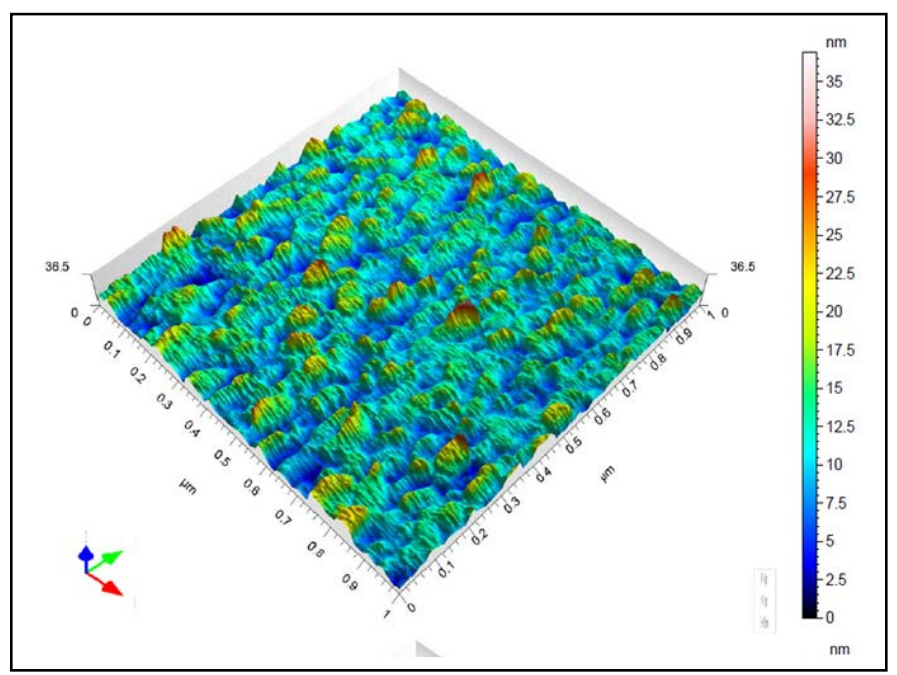

FIGURE VI.

THE AFM 3D IMAGE OF SAMPLE C

After analyzing the surface samples, the values of surface stereometric parameters were collected (Table II). These parameters were determined according to ISO 25178 standard and EUR 15178N standard [23-30].

TABLE II. 3-D SURFACE STEREOMETRIC PARAMETERS

\begin{tabular}{|l|c|c|c|}
\hline \multicolumn{4}{|c|}{ 3-D surface stereometric parameters } \\
\hline & Sample 1 & Sample 2 & Sample 3 \\
\hline Sq [nm] & 0.999 & 1.43 & 3.76 \\
\hline Ssk [-] & 0.524 & 0.102 & 0.795 \\
\hline Sku [-] & 4.68 & 3.24 & 4.21 \\
\hline Sp [nm] & 6.48 & 7.44 & 25.3 \\
\hline Sv [nm] & 5.71 & 6.80 & 11.6 \\
\hline Sz [nm] & 12.2 & 14.2 & 36.9 \\
\hline Sa [nm] & 0.760 & 1.13 & 2.93 \\
\hline \multicolumn{5}{|c|}{ EUR 15178N } \\
\hline Sz [nm] & 9.68 & 10.3 & 31.5 \\
\hline
\end{tabular}

\section{Discussions}

The deposition time for the samples was as the following: sample A: 7 minutes, sample B: 10 minutes and sample C: 13 minutes. After leveling and shape disposal, the images did not change, because the operations had been performed earlier.

The data from the identification cards for each sample are the same against $\mathrm{X}$ - and $\mathrm{Y}$-axes. Only the offset value for the sample 3 is different. On the other hand, this information is more varied against the Z-axis. All the samples were logged in 256 points which fall 256 scanning lines. The measurements of each sample in $\mathrm{X}$ and $\mathrm{Y}$-axes account $1 \mu \mathrm{m} \times 1 \mu \mathrm{m}$, and in Z-axis: $12.2 \mathrm{~nm}$ - sample A, $14.2 \mathrm{~nm}$ - sample B, $0.00 \mathrm{~nm}$ sample C.

There were eight altitude parameters for the above samples, Table II).

The largest root mean height $(\mathrm{Sq})$ shows the sample $\mathrm{C}$ $(3.76 \mathrm{~nm})$, whereas the lowest one has the sample A (0.999 $\mathrm{nm})$. This parameter indicates the root mean square of a measured surface.

The surface skewness (Ssk) of all three samples is positive (Ssk $>0$ ). It indicatives of the dominance of peaks on their surface, and the highest number of them has the sample $\mathrm{C}$ (0.795), while the lowest number of peaks has the sample B (0.102).

The surface kurtosis (Sku) for each sample reaches the value above 3.00 . Hence, it can be concluded that there are excessively high peaks or valleys on the surface with the highest value for the sample A (4.68). However, the lowest value appears in the sample B (3.24).

As far as the Sp and Sv parameters are considered, the highest maximum peak height and the largest pit height can be observed in the sample C $(\mathrm{Sp}=25.3 \mathrm{~nm}$, Sv $=11.6 \mathrm{~nm})$, whereas the lowest values of these parameters are reached by the sample A $(\mathrm{Sp}=6.48 \mathrm{~nm}, \mathrm{~Sv}=5.71 \mathrm{~nm})$. In addition, the sample $\mathrm{C}$ has the following values for the parameters: $\mathrm{Sp}=$ $7.44 \mathrm{~nm}, \mathrm{~Sv}=6.80 \mathrm{~nm}$.

On the basis of this information, it may be said that the greatest value of $\mathrm{Sz}$ parameter (i.e. the sum of the maximum peak height value and the maximum pit height value) has the sample C (36.9 $\mathrm{nm})$, and the least value is observed in the sample A $(12.2 \mathrm{~nm})$.

The highest arithmetic mean surface height (Sa) also appears in the sample C $(2.93 \mathrm{~nm})$, while the lowest one in the sample A $(0.760 \mathrm{~nm})$. These values also represent the arithmetic means of vertical deviations of the surface from the mean surface.

The last obtained parameter was the Sz parameter (defined in the EUR $15178 \mathrm{~N}$ standard) which was used to determine the heights of ten surface points. The sample $\mathrm{C}$ for this parameter shows the highest value $(31.5 \mathrm{~nm})$, and the sample A the lower value $(9.68 \mathrm{~nm})$. The sample with the deposition time of 13 minutes is found to be the sample that has the highest values of altitude parameters (except for the parameter Sku). 


\section{CONCLUSION}

The 3-D analysis of surface topography plays a significant role in the characteristics of material properties and functionality which may have various applications in technique. The stereometric analysis was conducted by means of MountainsMap ${ }^{\circledR}$ Premium software of the AFM images. It can be seen that the time deposition had an influence on the obtained values of the altitude parameters. The differences in the surface topography have been observed in each examined sample. The combination of RF-sputtering and RF-PECVD techniques represents a suitable route to prepare the NickelCarbon nanocomposite thin films composed of $\mathrm{Ni}$ nanoparticles with different average sizes embedded in amorphous hydrogenated carbon. Furthermore, all these morphological parameters can be used in various mathematical models to describe the local topography of the 3-D sample surface textures.

\section{ACKNOWLEDGMENT}

The authors would also like to thank to PhD. Ali Arman, Young Researchers and Elite Club, Kermanshah Branch, Islamic Azad University, Kermanshah, Iran, for his helpful advice and stimulating discussions during this study.

\section{REFERENCES}

[1] S. Ţălu, C. Luna, A. Ahmadpourian, A. Achour, A. Arman, S. Naderi, N. Ghobadi, S. Stach, and B. Safibonab, "Micromorphology and fractal analysis of nickel-carbon composite thin films,” J. Mater. Sci. Mater. Electron, vol. 27(11), pp. 11425-11431, 2016.

[2] A. Arman, T. Ghodselahi, M. Molamohammadi, S. Solaymani, H. Zahrabi, and A. Ahmadpourian, "Microstructure and Optical Properties of Cu@Ni Nanoparticles Embedded in aC:H,” Prot. Met. Phy. Chem, vol. 51(4), pp. 575-578, 2015.

[3] M. Molamohammadi, A. Arman, A. Achour, B. Astinchap, A. Ahmadpourian, A. Boochani, S. Naderi, and A. Ahmadpourian, "Microstructure and optical properties of cobalt-carbon nanocomposites prepared by RF-sputtering,” J. Mater. Sci. Mater. Electron, vol. 26(8), pp. 5964-5969, 2015.

[4] V. Dalouji, S. M. Elahi, and S. Naderi, "Surface plasmon resonance and electrical properties of RF: magnetron sputtered carbon-nickel composite films at different annealing temperatures," Rare Metals, vol. 35(11), pp. 863-869, 2016.

[5] M. Berndt, M. Krause, G. Abrasonis, A. Mucklich, F. Munnik, A. Kolitsch, and W. Moller, "Morphology and Structure of C:Co, C:V, and C:Cu Nanocomposite Films,” Plasma Process. Polym., vol. 6, pp. S902S906, 2009.

[6] F. C. Fonseca, A. S. Ferlauto, F. Alvarez, G. F. Goya, and R. F. Jardim, "Morphological and magnetic properties of carbon-nickel nanocomposite thin films,” J. Appl. Phys., vol. 97(4), 044313, 2005.

[7] A. Arman, C. Luna, M. Mardani, F. Hafezi, A. Achour, and A. Ahmadpourian, "Magnetoresistance of nanocomposite copper/carbon thin films,” J. Mater. Sci. Mater. Electron, vol. 28(6), pp. 4713-4718, 2017.

[8] V. Kumar Joshi, "Spintronics: A contemporary review of emerging electronics devices,” JESTECH, vol. 19(3), pp. 1503-1513, 2016.

[9] T. Ghodselahi, and A. Arman, "Magnetoresistance of $\mathrm{Cu}-\mathrm{Ni}$ nanoparticles in hydrogenated amorphous carbon thin films,” J. Mater. Sci. Mater. Electron, vol. 26(6), pp. 4193-4197, 2015.

[10] V. Dalouji, and S. M. Elahi, "Effect of annealing temperature on the optical loss and the optical constants of RF-magnetron sputtered carbon nickel composite films,” JKPS, vol. 64(6), pp. 857-862, 2014.

[11] G. Abrasonis, T. W. H. Oates, G. J. Kovács, J. Grenzer, Per O. Å. Persson, K.-H. H. Heinig, A. Martinavičius, N. Jeutter, C. Baehtz, M.
Tucker, M. M. M. Bilek, and Wolfhard Möller, "Nanoscale precipitation patterns in carbon-nickel nanocomposite thin films: Period and tilt control via ion energy and deposition angle,” J. Appl. Phys., vol. 108, 043503, 2010. DOI: 10.1063/1.3467521.

[12] M. Molamohammadi, C. Luna, A. Arman, S. Solaymani, A. Boochani, A. Ahmadpourian, and A. Shafiekhani, "Preparation and magnetoresistance behavior of nickel nanoparticles embedded in hydrogenated carbon film,” J. Mater. Sci. Mater. Electron, vol. 26(9), pp. 6814-6818, 2015.

[13] E. Grigore, A.A. El Mel, A. Granier, and P.Y. Tessier, "The influence of $\mathrm{Ni}$ content on the characteristics of C-Ni thin films," Surf. Coat. Technol., vol. 211, pp. 188-191, 2012.

[14] M. Stüber, H. Leiste, S. Ulrich, H. Holleck, and D. Schild "Microstructure and properties of low friction TiC C nanocomposite coatings deposited by magnetron sputtering", Surf. Coat. Technol., vol. 150, pp. 218-226, 2002.

[15] A.A. El Mel, B. Angleraud, E. Gautron, A. Granier, and P.Y. Tessier "Microstructure and composition of TiC/a-C:H nanocomposite thin films deposited by a hybrid IPVD/PECVD process", Surf. Coat. Technol. 204, pp. 1880-1883, 2010. DOI:10.1016/j.surfcoat.2009.09.045.

[16] T. Zehnder, P. Schwaller, F. Munnik, S. Mikhailov and J. Patscheider "Nanostructural and mechanical properties of nanocomposite nc-TiC/a$\mathrm{C}: \mathrm{H}$ films deposited by reactive unbalanced magnetron sputtering,” J. Appl. Phys., vol. 95(8), pp. 4327, 2004. DOI: 10.1063/1.1650898.

[17] E. Lewin, M. Gorgoi, F. Schäfers, S. Svensson, and U. Jansson "Influence of sputter damage on the XPS analysis of metastable nanocomposite coatings", Surf. Coat. Technol., vol. 204, pp. 455-462, 2009.

[18] R. Koppert, D. Goettel, O. Freitag-Weber, and G. Schultes "Nickel containing diamond like carbon thin films," Solid State Sci., vol. 11(10), pp. 1797-1800, 2009. DOI: 10.1016/j.solidstatesciences.2009.04.022.

[19] N. Dwivedi, S. Kumar, H.K. Malik, C. Sreekumar, S. Dayal, C.M.S. Rauthan, and O.S. Panwar "Investigation of properties of Cu containing DLC films produced by PECVD process", J. Phys. Chem. Solids. 73, pp. 308-316, 2012. DOI: 10.1016/j.jpcs.2011.10.019.

[20] N. Bouts, M. Gaillard, L. Donero, A.A. El Mel, E. Gautron, B. Angleraud, C. Boulmer-Leborgne, and P.Y. Tessier "Growth control of carbon nanotubes using nanocomposite nickel/carbon thin films," Thin Solid Films, vol. 630, pp. 38-47, 2017. DOI: 10.1016/j.tsf.2016.10.025.

[21] B. Bayatsarmadi, Y. Zheng, V. Russo, L. Ge, C. S. S. Casari and S. Qiao "Highly active nickel-cobalt/nanocarbon thin films as efficient water splitting electrodes,” Nanoscale, vol. 8 (43), pp. 18507-18515, 2016.

[22] MountainsMap ${ }^{\circledR} 7$ Software (Digital Surf, Besançon, France). Available from: http://www.digitalsurf.fr (last accessed October 10th, 2017).

[23] ISO 25178-2: 2012 Geometrical product specifications (GPS) - Surface texture: Areal -Part 2: Terms, definitions and surface texture parameters. (2012) http://www.iso.org. Last accessed October 10th, 2017.

[24] Ş. Țălu, Micro and nanoscale characterization of three dimensional surfaces. Basics and applications, Napoca Star Publishing House, ClujNapoca, Romania, 2015.

[25] Ş. Țălu, "Characterization of surface roughness of unworn hydrogel contact lenses at a nanometric scale using methods of modern metrology,” Polym. Eng. Sci., vol. 53(10), pp. 2141-2150, 2013.

[26] Ş. Țălu, and S. Stach, "Multifractal characterization of unworn hydrogel contact lens surfaces,” Polym. Eng. Sci., vol. 54(5), pp. 1066-1080, 2014.

[27] S. Stach, D. Dallaeva, Ş. Țălu, P. Kaspar, P. Tománek, S. Giovanzana, and L. Grmela, "Morphological features in aluminum nitride epilayers prepared by magnetron sputtering,” Mater. Sci. Poland, vol. 33(1), pp. 175-184, 2015.

[28] Ş. Țălu, S. Stach, S. Valedbagi, S.M. Elahi, and R. Bavadi, "Surface morphology of titanium nitride thin films synthesised by DC reactive magnetron sputtering,” Mater. Sci. Poland, vol. 33(1), pp. 137-143, 2015.

[29] S. Ramazanov, Ş. Țălu, D. Sobola, S. Stach, and G. Ramazanov, "Epitaxy of silicon carbide on silicon: Micromorphological analysis of growth surface evolution,” Superlattices and Microstructures, vol. 86, pp. 395-402, 2015. DOI: 10.1016/j.spmi.2015.08.007.

[30] Ş. Țălu, S. Stach, A. Méndez, G. Trejo, and M. Țălu, "Multifractal characterization of nanostructure surfaces of electrodeposited Ni-P coatings,” J Electrochem Soc., vol. 161, pp. D44-D47, 2014. 